\title{
Article
}

\section{The Mediating Role of Gender, Age, COVID-19 Symptoms and Changing of Mansion on the Mental Health of Healthcare Workers Operating in Italy during the First Wave of the COVID-19 Pandemic}

\author{
Eleonora Gambaro 1,2,*(D), Carla Gramaglia ${ }^{1,2}$, Debora Marangon ${ }^{2}$, Danila Azzolina ${ }^{1}$, Manuela Probo ${ }^{3}$, \\ Marco Rudoni ${ }^{3}$ and Patrizia Zeppegno ${ }^{1,2}$
}

1 Department of Translational Medicine, Università del Piemonte Orientale, 13100 Vercelli, Italy; carla.gramaglia@gmail.com (C.G.); danila.83@live.com (D.A.); patrizia.zeppegno@med.uniupo.it (P.Z.)

2 Psychiatry Unit, Maggiore della Carità Hospital, 28100 Novara, Italy; deboramarangon@libero.it

3 Department of Mental Health, ASL NOVARA, 28100 Novara, Italy; manuela.probo@asl.novara.it (M.P.); marco.rudoni@fastwebnet.it (M.R.)

* Correspondence: eleonora.gambaro22@gmail.com

Citation: Gambaro, E.; Gramaglia, C.; Marangon, D.; Azzolina, D.; Probo, M.; Rudoni, M.; Zeppegno, P. The Mediating Role of Gender, Age, COVID-19 Symptoms and Changing of Mansion on the Mental Health of Healthcare Workers Operating in Italy during the First Wave of the COVID-19 Pandemic. Int. J. Environ. Res. Public Health 2021, 18, 13083. https://doi.org/10.3390/ ijerph182413083

\section{Academic Editors:}

Vincenza Gianfredi and Andrea Amerio

Received: 27 September 2021 Accepted: 8 December 2021 Published: 11 December 2021

Publisher's Note: MDPI stays neutral with regard to jurisdictional claims in published maps and institutional affiliations.

Copyright: () 2021 by the authors. Licensee MDPI, Basel, Switzerland. This article is an open access article distributed under the terms and conditions of the Creative Commons Attribution (CC BY) license (https:// creativecommons.org/licenses/by/ $4.0 /)$.

\begin{abstract}
The COVID-19 pandemic has tested the performance of hospitals and intensive care units around the world. Health care workers (HCWs) have been used to developmental symptoms, but this was especially true during the COVID-19 pandemic when HCWs have been faced with many other sources of stress and anxiety that can usually be avoided. Moreover, long-term shifts and unprecedented population restrictions have weakened people's ability to cope with stress. The research aims to observe the dynamic interplay between burnout, depression, distress, and anxiety in HCWs working in various settings, with specific a focus on emotional exhaustion, depersonalization, and a diminished sense of personal achievement in mediating a worse mental health status during the first wave of the COVID-19 pandemic in Italy. We performed a mediation analysis, which resulted in a strong correlation among depression, psychological distress, health perception and anxiety, and the impact of job burnout on anxiety, depression, and distress. Gender seemed to have a strong correlation with burnout, anxiety, and distress; the impact of the COVID-19 pandemic on Quality of Life seemed to affect anxiety and depression; the possible changes in job tasks and duties (intended as a change in work area or location and role change)influenced depression and job burnout. Encouraging supportive and educational strategies would be recommended to policymakers.
\end{abstract}

Keywords: burnout; healthcare workers; mediation analysis; COVID-19 pandemic; mental health

\section{Introduction}

The WHO Emergency Committee declared a global health emergency on 30 January 2020, due to COVID-19 (coronavirus disease 2019; previously 2019nCoV) outbreak disease [1,2]. The cumulative number of global confirmed cases reported is now $254,847,065$, including $5,120,712$ deaths, reported to $\mathrm{WHO}$ and the cumulative number of deaths is 5,120,712 million. A total of 7,370,902,499 vaccine doses have been administered (data reported at 18 November 2021 Figure 1) [2]. COVID-19, as an unknown disease, requires in-depth studies and observations on the existence of the virus, thus posing itself as a new challenge for the scientific community. To contain the disease, develop prevention and treatment strategies, active loco-regional to international cooperation is necessary [3].

The pandemic of COVID-19 would force a re-definition of vital support personnel, with acknowledgement of all healthcare workers (HCWs) contributions and adequate education, defense, and compensation [4].

According to the COVID-19 Task Force of the Department of Infectious Diseases and the IT Service of the Italian Higher Institute of Health, the cases in the general population 
were $4,893,529$ ( $49 \%$ of whom males, $51 \%$ of whom females, with an average age equal to 45 years), the cases among healthcare workers (HCWs) were 148,045, deaths were 132,413 and cases cured were 4,487,286 (data updated as of 18 November 2021) [5].

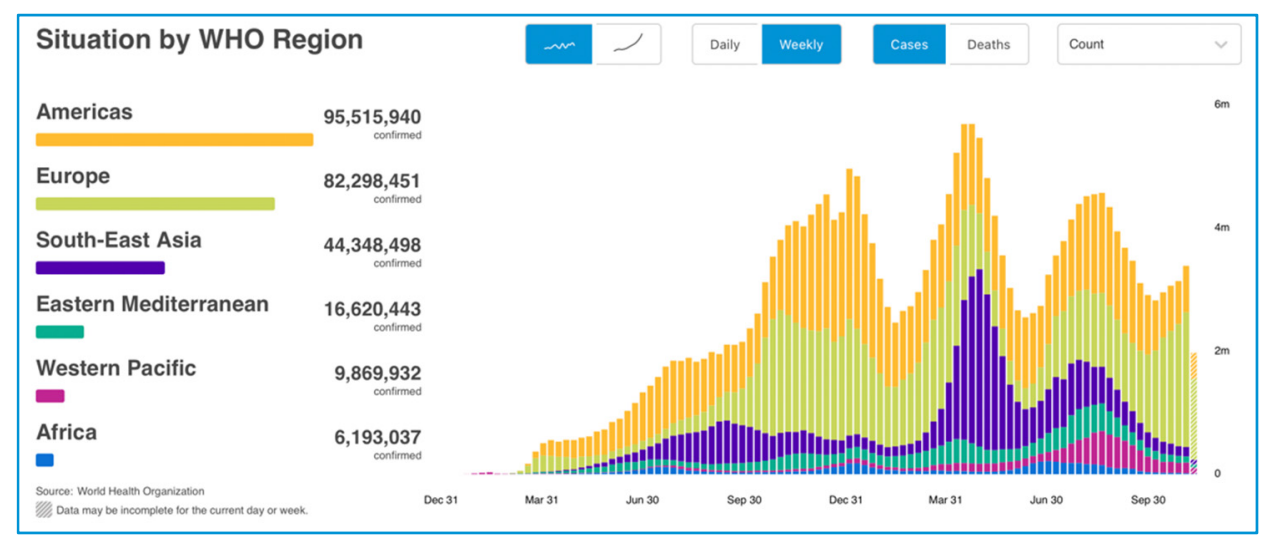

Figure 1. COVID-19 cases reported weekly by WHO Region, and global deaths, as of 18 November 2021 tried by World Health Organization 2021.

The COVID-19 pandemic has tested and, in many cases, surpassed hospital and intensive care unit (ICU) capabilities around the world [5]. Despite fatigue, personal risk of infection, fear of transmission to family members, sickness or death of friends and colleagues, and the loss of many patients, HCWs is a population of workers already used to developing anxiety, depression, burnout, insomnia, moral distress, and post-traumatic stress disorder [6], and have continued to provide care for patients. Furthermore, they have also had to cope with a slew of other issues as well as long shifts coupled with unprecedented population limits, such as personal isolation, have harmed people's ability to cope [7]. Loneliness has been exacerbated by working remotely and being shunned by community members [8].

Many HCWs travelled to new places of work as the pandemic progressed, often thrust into the pandemic ICU environment, with inadequate skills and training [9]. Hospitalbased HCWs have had to work long hours wearing bulky and uncomfortable personal protective equipment (PPE) [7].

The treatment of COVID-19 patients with chronic comorbidities has been particularly complex due to both the lack of funding and specific COVID-19 therapies [10]. Some HCWs have been faced with difficult decisions regarding resource rationing and withholding resuscitation or ICU admission causing emotional and ethically fraught dilemmas [11]. Moreover, because of the COVID-19 pandemic, surgeries or other life-saving treatments were cancelled or postponed, leading to anguish among recovered COVID-19 patients, an emotional experience shared by the attending physicians $[12,13]$.

HCWs' preparation (e.g., medical students, residents, and allied health learners) was also disrupted, resulting in tuition payments being lost, missed learning opportunities, missed tests, and possibly delayed certification [7,14]. COVID-19 was particularly relevant for female HCWs, where COVID-19 has had a disproportionately negative effect. Women make up $70 \%$ of the global health and social care workers, placing them at risk of illness and the variety of physical and mental health issues that come with their roles as health practitioners and caregivers [7]. Women have had to balance their professional obligations with their family's needs, including childcare, homeschooling, elder care, and home care $[15,16]$. Due to these commitments, women's academic productivity was lower than men's, as shown by the fact that fewer women were part of the cohort that generated new information about the pandemic [17].

Although it is known that extreme burnout syndrome affects up to $33 \%$ of critical care nurses and up to $45 \%$ of critical care physicians under normal working circumstances [18], nevertheless, data on impact of COVID-19 pandemic is not available. Surely, increased job 
pressures and little influence over the work environment, as well as the trauma of caring for critically ill patients, are significantly exacerbating factors for poor mental health among HCWs [19].

Burnout is a multi-faceted reaction to physiological, mental, or interpersonal work stressors that can lead to psychological issues, increased suicide, and drug abuse among HCWs [20]. Emotional exhaustion (EE), depersonalization (D), and a diminished sense of personal achievement (PA) are all symptoms of this condition [21]. A variety of factors can affect burnout risk, but encouraging mental health in policies, reducing HCW workload, mitigating job-related stressors, and favoring a healthy work environment can all help to prevent or reduce burnout [22].

In a previous study using an online survey [23], we evaluated the mental health effects of the first wave of the COVID-19 pandemic on HCWs in North-Eastern Piedmont, a high-risk region in Italy. Our study analyzed HCWs from various settings (hospital and community healthcare facilities, emergency, and non-emergency services), including also HCWs not directly involved in the treatment of patients affected by the COVID-19 disease, to observe the dynamic interplay between burnout, depression, distress, and anxiety in HCWs working in various settings, with a specific focus on EE, D, and a diminished PA in mediating a worst mental health status.

Based on the research findings reported above, the objective of the study was to explore: (1) whether a relationship between job burnout and perceived stress, anxiety, and depression exists among HCWs; (2) whether socio-demographic and anamnestic characteristics could act as a mediator in the relationship between job burnout and perceived stress, anxiety, and depression.

\section{Materials and Methods}

The study protocol was approved by the local Ethical Board (Comitato Etico Interaziendale di Novara, Protocollo 534/CE, Studio n. CE 82/20, approved on 11 May 2020). The survey was implemented with the REDCap platform and e-mailed at the end of the first wave of the COVID pandemic emergency crisis period (in June 2020) on behalf of the human resources offices in charge of the healthcare institutions detailed below, who have access to the mailing lists including the institutional e-mail contacts of all HCWs employees. The procedure for the implementation and diffusion of the survey have been already described in detail elsewhere [23].

The online survey presented the objectives of the research; HCWs were required to give their informed consent to participate.

The first part of the online survey included general information, questions about the professional role and possible changes in job tasks and duties (intended as a change in work area or location and role change) during the peak of the pandemic. Regarding the reality of Novara, Italy, all ordinary leave was suspended; resources were redistributed by reducing the number of beds and therefore the number of personnel assigned to ordinary departments to allocate them to crisis departments. The territorial network was also strengthened to monitor cases in isolation/quarantine and to identify possible contacts of ascertained cases. Some private health facilities have also been used to treat patients with COVID-19. The medical staff was reorganized in the various departments so that structured doctors with expertise in the management of respiratory patients were placed at the forefront, with a coordinating role: internists, pulmonologists, infectious diseases, anesthetists. These were supported $24 \mathrm{~h}$ a day by colleagues from the remaining support departments. Doctors in specialist training were also located to support wards with COVID19 patients, carrying out back-office activities. The reorganization also provided for the redistribution of nursing staff and social and health workers.

Standardized and validated self-administered measures were used for the assessment of burnout (Maslach Burnout Inventory-Human Services Survey for Medical PersonnelMBI-HSS MP) [24], overall health perception (General Health Questionnaire-12 ItemsGHQ) [25], distress perceived because of stressing life events (Impact of Event Scale- 
IES) [26], depression (Beck Depression Inventory-BDI) [27] and anxiety (Beck Anxiety Inventory-BAI) [28].

MBI-HSS MP is a 22-items scale, with each item scored on a 7-point (ranging from 0 , "never," to 6 "every day"). It evaluates individuals' experience of occupational burnout in individuals who work with people (human services and medical professionals), with three components: EE, D, and reduced PA. Each subscale score can then be coded as "low," "average" or "high" according to the scoring key, and is considered separately from the other, without combining into a single, total score. GHQ was developed for non-clinical populations to detect a wide range of disorders, and specifically the anxiety/depression spectrum; it is a valid and reliable instrument across cultures. The items are rated on a 4point scale ("less than usual," "no more than usual," "rather more than usual," "much more than usual") offering a total score ranging from 0 to 36 points, with higher scores indicating worse mental well-being. IES consists of 15-items, rated on a 4-point scale according to how often each has occurred in the past 7 days $(0=$ not at all; $1=$ rarely; $3=$ sometimes; $5=$ often $)$. Besides the IES total subjective stress score, two subscales are identified: one for intrusive symptoms (intrusive thoughts, nightmares, intrusive feelings, and imagery; seven items, scores ranging from 0 to 35), and one for avoidance symptoms (numbing of responsiveness, avoidance of feelings, situations, ideas; eight items, scores ranging from 0 to 40). The IES has also displayed the ability to discriminate a variety of traumatized groups from non-traumatized groups. Even if, the questionnaire evaluating trauma used in this study was not the Impact of Event Scale with modifications for 2019-nCOVID (IES-COVID19), the protocol was specified to answer the IES questions considering "event", everything that was related to the 2019-nCOVID pandemic. BAI is a 21-item scale for the assessment of anxiety symptoms severity. Each item is rated on a 4-point scale (from $0=$ not at all to 3 = severely, can barely stand it), focusing on the past week experience. The final score, obtained from the sum of the individual items, is between 0 and $63(\leq 21=$ minimum level of anxiety; $22-35=$ medium level of anxiety; $\geq 36$ = high level of anxiety). BDI is a 21 -item self-report inventory measuring the severity of depression. Each item is scored on a 4-point scale. In this inventory, the higher is the total score, the more severe is depression; standardized cutoff values are the following: $0-13=$ minimal depression; $14-19=$ mild depression; 20-28 = moderate depression; 29-63 = severe depression.

In our sample of HCWs, four main subgroups could be identified: medical doctors/physicians, residents in training (meaning graduated medical doctors attending specialization schools), nurses and "others" (this group included participants who did not fit any of the previous categories, such as psychologists, social workers, radiology and laboratory technicians, educators).

\section{Statistical Analysis}

Data have been synthesized in terms of absolute and relative frequencies for the categorical variables and as median and interquartile range (Q1-Q3) for the continuous variables.

Mediation analysis has been carried out via Structural Equation Model (SEM) computation.

All endogenous dependent variables are quantitative; the Pearson correlation matrix with associated densities and histograms have been reported for these variables.

The biserial (polyserial) correlations have been reported for the continuous and binary (ordinal) variables and Tetrachoric (or Polycoric) correlations for binary (ordinal) variables. The intercepts in the SEM were set to zero. The dichotomous variables used in the SEM model (gender, change in habits during the pandemic, etc.) are exogenous (independent). Those variables have been recorded as a dummy $(0 / 1)$ variable like in a classic regression model as suggested in the literature [29]. The age in classes variable is ordinal and exogenous, the encoding scheme reflects the order (say, 1,2,3, . ) and has been treated like any other (numeric) covariate [29].

The computations have been conducted with R 3.4.2 [30] with the lavaan [29] packages (R Foundation for Statistical Computing, Vienna, Austria). 


\section{Results}

\section{Description of the Sample}

The online survey was e-mailed to $2422 \mathrm{HCWs}$ and completed by 897 (37\%) respondents. In total, only 653 out of these 897 (73\%) completed the questionnaires in full. The 244 incomplete records were thus excluded from the statistical analyses.

210 HCWs were male (32.2\%), 443 HCWs were female (67.8\%). 92 HCWs were aged $18-29$ years $(14.1 \%), 189 \mathrm{HCWs}$ were aged $30-39$ years $(51 \%), 145 \mathrm{HCWs}$ were aged $40-49$ years female $(22.2 \%), 227 \mathrm{HCWs}$ were aged $\geq 50$ years $(34.8 \%) .159 \mathrm{HCWs}$ were single/divorced/widow (24.3\%), $413 \mathrm{HCWs}$ were married/cohabitant $(63.2 \%), 81 \mathrm{HCWs}$ in a stable relationship (12.4\%), $358 \mathrm{HCWs}$ had children (54.8\%), $295 \mathrm{HCWs}$ did not have children $(45.2 \%)$.

Regarding the MBI-HSS MP scale, the median EE is 18 (moderate), D is 18 (high) and PA is 32 (high), indicative of moderate-high levels of burnout. The median IES scale is 19 (mild subjective stress), the median GHQ scale is 18 (perception to have some health problems). The median BAI and BDI scale are 8 (mild anxiety, low depression).

Doctors/physicians comprised $286 \mathrm{HCWs}(43.8 \%)$, 99 HCWs were residents in training $(15.2 \%), 137 \mathrm{HCWs}$ were nurses $(21.0 \%), 131 \mathrm{HCW}$ s were other professionals $(20.1 \%)$. Positive test results for a COVID-19 swab were 89 HCWs (13.6\%), 125 had COVID-19 related symptoms (19.1\%). $556 \mathrm{HCWs}$ did not have COVID-19 related health problems $(85.1 \%)$. A total of $322 \mathrm{HCWs}$ modified their job due to the COVID-19 pandemic (49.3\%), $331 \mathrm{HCWs}$ did not modify their job due to the COVID-19 pandemic (50.7\%). HCWs who had someone close to them test positive to a COVID-19 swab were $454(69.5 \%), 199 \mathrm{HCWs}$ did not have someone close test positive to a COVID-19 swab (30.5\%). A total of $43 \mathrm{HCWs}$ modified family habits for fear of infecting a loved one (6.6\%), $525 \mathrm{HCWs}$ did not modify family habits for fear of infecting loved one dear (80.45), $85 \mathrm{HCWs}$ did not answer the question related to modification of family habits for fear of infecting loved one dear $(13.0 \%)$. All results are shown in Table 1.

Table 1. Descriptive data of the sample, including socio-demographic and work-related variables. The median and quartiles (Q1-Q3) have been reported for the continuous variables and the absolute with relative \% frequencies for the categorical ones.

\begin{tabular}{|c|c|c|c|c|}
\hline & Variables & & $\begin{array}{c}n \\
\text { Median }\end{array}$ & $\begin{array}{c}\% \\
\text { Q1-Q3 }\end{array}$ \\
\hline \multirow{3}{*}{ MBI-HSS MP } & EE & Emotional Exhaustion & 18 & $11-26$ \\
\hline & $\mathbf{D}$ & Depersonalization & 10 & $7-14$ \\
\hline & PA & Personal Accomplishment & 32 & $28-36$ \\
\hline IES & & Impact of Event Scale & 19 & $6-33$ \\
\hline GHQ-12 & & General Health Questionnaire & 18 & $17-22$ \\
\hline BAI & & Beck Anxiety Inventory & 8 & $4-14$ \\
\hline BDI-II & & Beck's Depression Inventory & 8 & $3-14$ \\
\hline \multirow{2}{*}{ Gender } & & Male & 210 & $32.2 \%$ \\
\hline & & Female & 443 & $67.8 \%$ \\
\hline
\end{tabular}


Table 1. Cont.

\begin{tabular}{|c|c|c|c|}
\hline \multicolumn{2}{|l|}{ Variables } & $\begin{array}{c}n \\
\text { Median }\end{array}$ & $\begin{array}{c}\% \\
\text { Q1-Q3 }\end{array}$ \\
\hline \multirow{4}{*}{ Age categories } & $18-29$ years & 92 & $14.1 \%$ \\
\hline & 30-39 years & 189 & $28.9 \%$ \\
\hline & $40-49$ years & 145 & $22.2 \%$ \\
\hline & $\geq 50$ years & 227 & $34.8 \%$ \\
\hline \multirow{3}{*}{ Marital status } & Single/divorced/widow & 159 & $24.3 \%$ \\
\hline & Married/cohabitant & 413 & $63.2 \%$ \\
\hline & In a stable relationship & 81 & $12.4 \%$ \\
\hline \multirow{2}{*}{ Children } & Yes & 358 & $54.8 \%$ \\
\hline & No & 295 & $45.2 \%$ \\
\hline \multirow{4}{*}{ Working categories } & Doctors/Physicians & 286 & $43.8 \%$ \\
\hline & Residents in training & 99 & $15.2 \%$ \\
\hline & Nurses & 137 & $21.0 \%$ \\
\hline & Others * & 131 & $20.1 \%$ \\
\hline \multirow{2}{*}{ Positivity to COVID-19 swab } & No & 564 & $86.4 \%$ \\
\hline & Yes & 89 & $13.6 \%$ \\
\hline \multirow{2}{*}{ COVID-19 related symptoms } & No & 528 & $80.9 \%$ \\
\hline & Yes & 125 & $19.1 \%$ \\
\hline \multirow{2}{*}{ Health problems not related to COVID-19 } & No & 556 & $85.1 \%$ \\
\hline & Yes & 97 & $14.9 \%$ \\
\hline \multirow{2}{*}{$\begin{array}{l}\text { Changing of mansion due to the } \\
\text { COVID-19 pandemic }\end{array}$} & No & 89 & $13.6 \%$ \\
\hline & Yes & 564 & $86.4 \%$ \\
\hline \multirow{2}{*}{ Job modification due to the COVID-19 pandemic } & No & 322 & $49.3 \%$ \\
\hline & Yes & 331 & $50.7 \%$ \\
\hline \multirow{2}{*}{ Someone of dear positive to COVID-19 swab } & No & 454 & $69.5 \%$ \\
\hline & Yes & 199 & $30.5 \%$ \\
\hline \multirow{3}{*}{$\begin{array}{l}\text { Modification of family habits for fear of infecting } \\
\text { loved one dear }\end{array}$} & No & 43 & $6.6 \%$ \\
\hline & Yes & 525 & $80.4 \%$ \\
\hline & No answer & 85 & $13.0 \%$ \\
\hline \multirow{2}{*}{ Gender } & Male & 210 & $32.2 \%$ \\
\hline & Female & 443 & $67.8 \%$ \\
\hline \multirow{4}{*}{ Age categories } & 18-29 years & 92 & $14.1 \%$ \\
\hline & 30-39 years & 189 & $28.9 \%$ \\
\hline & $40-49$ years & 14 & $22.2 \%$ \\
\hline & $\geq 50$ years & 227 & $34.8 \%$ \\
\hline \multirow{3}{*}{ Marital status } & Single/divorced/widow & 159 & $24.3 \%$ \\
\hline & Married/cohabitant & 413 & $63.2 \%$ \\
\hline & In a stable relationship & 81 & $12.4 \%$ \\
\hline \multirow{2}{*}{ Children } & Yes & 358 & $54.8 \%$ \\
\hline & No & 295 & $45.2 \%$ \\
\hline
\end{tabular}


Table 1. Cont.

\begin{tabular}{|c|c|c|c|}
\hline \multicolumn{2}{|l|}{ Variables } & $\begin{array}{c}n \\
\text { Median }\end{array}$ & $\%$ \\
\hline \multirow{4}{*}{ Working categories } & Doctors/Physicians & 286 & $43.8 \%$ \\
\hline & Residents in training & 99 & $15.2 \%$ \\
\hline & Nurses & 137 & $21.0 \%$ \\
\hline & Others * & 131 & $20.1 \%$ \\
\hline \multirow{2}{*}{ Positivity to COVID-19 swab } & No & 564 & $86.4 \%$ \\
\hline & Yes & 89 & $13.6 \%$ \\
\hline \multirow{2}{*}{ COVID-19 related symptoms } & No & 528 & $80.9 \%$ \\
\hline & Yes & 125 & $19.1 \%$ \\
\hline \multirow{2}{*}{ Health problems not related to COVID-19 } & No & 556 & $85.1 \%$ \\
\hline & Yes & 97 & $14.9 \%$ \\
\hline \multirow{2}{*}{$\begin{array}{l}\text { Changing of mansion due to the } \\
\text { COVID-19 pandemic }\end{array}$} & No & 89 & $13.6 \%$ \\
\hline & Yes & 564 & $86.4 \%$ \\
\hline \multirow{2}{*}{ Job modification due to the COVID-19 pandemic } & No & 322 & $49.3 \%$ \\
\hline & Yes & 331 & $50.7 \%$ \\
\hline \multirow{2}{*}{ Someone of dear positive to COVID-19 swab } & No & 454 & $69.5 \%$ \\
\hline & Yes & 199 & $30.5 \%$ \\
\hline \multirow{3}{*}{$\begin{array}{l}\text { Modification of family habits for fear of infecting } \\
\text { loved one dear }\end{array}$} & No & 43 & $6.6 \%$ \\
\hline & Yes & 525 & $80.4 \%$ \\
\hline & No answer & 85 & $13.0 \%$ \\
\hline \multicolumn{4}{|c|}{ Cut-off Scoring Questionnaires } \\
\hline MHBI-HSS MP & High & Moderate & Low \\
\hline EE & $>30$ & $18-29$ & $<17$ \\
\hline $\mathbf{D}$ & $>12$ & $06-11$ & $<5$ \\
\hline PA & $<34$ & $35-39$ & $>40$ \\
\hline Severe & Moderate & Mild & Subclinical \\
\hline \multirow[t]{2}{*}{ IES TOT } & $26-43$ & $9-25$ & $0-8$ \\
\hline & Several Problems & Some Problemes & No problems \\
\hline \multirow[t]{2}{*}{ GHQ-12 TOT } & $20-36$ & 15-19 & $0-14$ \\
\hline & High & Moderate & Low \\
\hline BAI TOT & $>36$ & $22-35$ & $0-21$ \\
\hline Severe & Moderate & Mild & Minimal \\
\hline BDI-II TOT & $20-28$ & 14-19 & $0-13$ \\
\hline
\end{tabular}

$n=$ number of participants. $\%=$ percentage of individuals. ${ }^{*}=$ psychologists, socio-health, psychological, radiological and laboratory technicians, educators. Medical Personnel (MBI-HSS MP), Emotional Exhaustion (EE), Depersonalization (DP), Personal Accomplishment (PA), Beck Depression Inventory (BDI-II), Beck Anxiety Inventory (BAI), Impact of Event Scale (IES) and General Health Questionnaire 12 Items (GHQ-12).

The statistical significance of the mediating effect was confirmed by the Sobel test. The SEM yielded a good fit to the observed data indicating the direct pathway from job burnout and perceived stress, anxiety or depression and the indirect pathway, which was mediated by other characteristics. As shown in Figure 2 and Table 2, the direct effect of perceived stress on job burnout was estimated in the model (the model fit of the data $\chi 2 / \mathrm{df}<5$, $p<0.05)$, which was found to be not statistically significant and positive $(\beta=0.28)$; there 
were statistically significant effects of perceived stress (IES) on both anxiety ( $\beta=0.61$ ) and depression $(\beta=0.58)$. Moreover, there seems to exist statistically significant effects of depression on anxiety $(\beta=0.78)$ and health perception on depression $(\beta=0.68)$ and anxiety $(\beta=0.56)$. The coefficients of perceived stress on job burnout were significantly reduced $(\beta=0.28)$ as also for health perception on perceived stress $(\beta=0.44)$ and job burnout $(\beta=0.36)$.

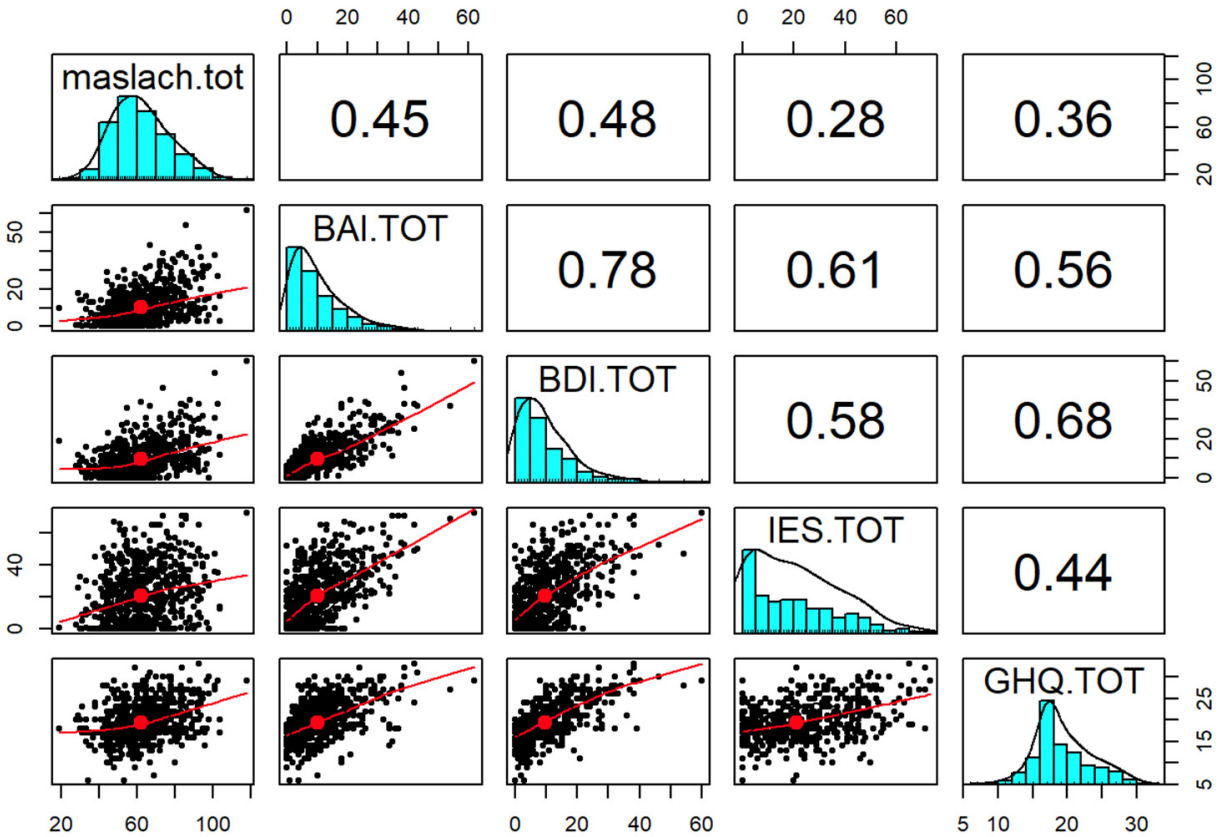

Figure 2. Observed Pearson correlations among Medical Personnel (MBI-HSS MP), Beck Depression Inventory (BDI-II), Beck Anxiety Inventory (BAI), Impact of Event Scale (IES) and General Health Questionnaire 12 Items (GHQ-12).

Table 2. The model implied (fitted) correlation matrix among Medical Personnel (MBI-HSS MP), Beck Depression Inventory (BDI), Beck Anxiety Inventory (BAI), Impact of Event Scale (IES) and General Health Questionnaire (GHQ), Age categories, Gender, COVID-19 related symptoms, Changing of mansion due to the COVID-19 pandemic.

\begin{tabular}{|c|c|c|c|c|c|c|c|}
\hline Variables & Maslach Total & BAI Total & BDI-II Total & IES Total & GHQ-12 Total & Age Categories & Gender \\
\hline Maslach Total & 1.000 & & & & & & \\
\hline BAI Total & 0.760 & 1.000 & & & & & \\
\hline BDI Total & 0.786 & 0.912 & 1.000 & & & & \\
\hline IES Total & 0.749 & 0.872 & 0.848 & 1.000 & & & \\
\hline GHQ Total & 0.660 & 0.734 & 0.775 & 0.701 & 1.000 & & \\
\hline Age categories & -0.324 & -0.297 & -0.233 & -0.045 & -0.156 & 1.000 & \\
\hline Gender & 0.517 & 0.656 & 0.576 & 0.855 & 0.458 & -0.023 & 1.000 \\
\hline COVID-19 related symptoms & 0.168 & 0.520 & 0.495 & 0.319 & 0.397 & 0.025 & 0.020 \\
\hline $\begin{array}{l}\text { Changing of mansion due to } \\
\text { the COVID-19 pandemic }\end{array}$ & 0.716 & 0.466 & 0.582 & 0.502 & 0.538 & -0.091 & 0.147 \\
\hline
\end{tabular}

In the second phase of mediation analysis (Figure 3 and Table 3), the three variable scales of the MBI-HSS (MP) questionnaire were considered individually, i.e., EE, which measures feelings of being emotionally overextended and exhausted by one's work, D that measures an unfeeling and impersonal response toward patients, and PA those measures feelings of competence and achievement in one's work. From this analysis it emerged that there were statistically significant effects of EE on D $(\beta=0.58), P A(\beta=0.14)$ anxiety $(\beta=0.53)$ and depression, and less significant effects on psychological distress $(\beta=0.32)$ and health perception $(\beta=0.46)$. Regarding $D$, it showed lower statistically significant 
effects on anxiety $(\beta=0.37)$, depression $(\beta=0.40)$, psychological distress $(\beta=0.19)$, and health perception $(\beta=0.27)$, but greater statistically significant effects on the reduction of $\mathrm{PA}$, indicative of higher burnout $(\beta=-0.01)$.

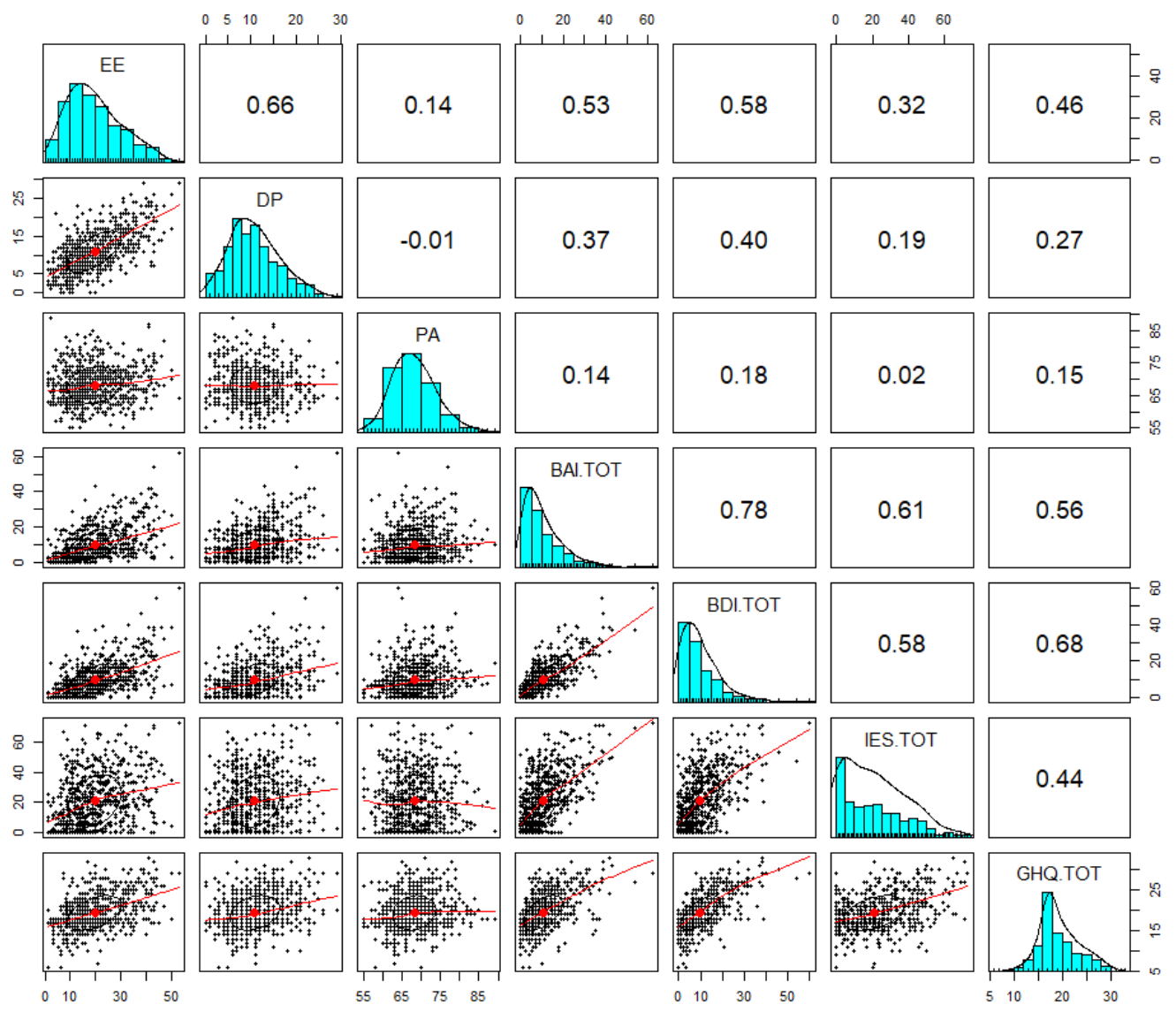

Figure 3. Observed Pearson correlation among Emotional Exhaustion (EE), Depersonalization (DP), Personal Accomplishment (PA), Beck Depression Inventory (BDI-II), Beck Anxiety Inventory (BAI), Impact of Event Scale (IES) and General Health Questionnaire 12 Items (GHQ-12).

Finally, effects of a low PA were particularly significant on perceived stress $(\beta=0.02)$, but also on anxiety $(\beta=0.14)$, health perception $(\beta=0.15)$, and depression $(\beta=0.18)$.

Four covariates were included in the mediation analysis: age, gender, COVID-19 related symptoms, and changing of mansion due to the COVID-19 pandemic. As shown in Figures 4 and 5, Tables 4-6 emerged as showing that the covariates were not very correlated with each other. Moreover, a statistically significant effect emerged of gender on anxiety ( $\beta=0.656)$ and psychological distress $(\beta=0.855)$, and of changing of mansion due to the COVID-19 pandemic on Maslach total $(\beta=0.716)$, health perception $(\beta=0.538)$, depression $(\beta=0.582)$, and perceived stress $(\beta=0.502)$. Finally, it emerged that COVID-19 related symptoms had statistically significant effects on anxiety $(\beta=0.520)$, but weaker ones on depression $(\beta=0.495)$, perceived stress $(\beta=0.319)$, and health perception $(\beta=0.397)$. 
Table 3. Model implied (fitted) among Emotional Exhaustion (EE), Depersonalization (DP), Personal Accomplishment (PA), Beck Depression Inventory (BDI-II), Beck Anxiety Inventory (BAI), Impact of Event Scale (IES) and General Health Questionnaire 12 Items (GHQ-12), Age categories, Gender, COVID-19 related symptoms, Changing of mansion due to the COVID-19 pandemic.

\begin{tabular}{|c|c|c|c|c|c|c|c|c|c|c|c|}
\hline Variables & EE & DP & PA & $\begin{array}{l}\text { BAI } \\
\text { Total }\end{array}$ & $\begin{array}{c}\text { BDI-II } \\
\text { Total }\end{array}$ & $\begin{array}{l}\text { IES } \\
\text { Total }\end{array}$ & $\begin{array}{c}\text { GHQ- } \\
12 \\
\text { Total }\end{array}$ & $\begin{array}{l}\text { Age Cat- } \\
\text { egories }\end{array}$ & Gender & $\begin{array}{l}\text { COVID- } \\
19 \text { Related } \\
\text { Symp- } \\
\text { toms }\end{array}$ & $\begin{array}{c}\text { Changing of } \\
\text { Mansion } \\
\text { due to the } \\
\text { COVID-19 } \\
\text { Pandemic }\end{array}$ \\
\hline $\mathrm{EE}$ & 1.000 & & & & & & & & & & \\
\hline $\mathrm{DP}$ & 0.360 & 1.000 & & & & & & & & & \\
\hline PA & 0.228 & 0.079 & 1.000 & & & & & & & & \\
\hline BAI Total & 0.803 & 0.286 & 0.302 & 1.000 & & & & & & & \\
\hline BDI-II Total & 0.806 & 0.316 & 0.289 & 0.912 & 1.000 & & & & & & \\
\hline IES Total & 0.843 & 0.108 & 0.219 & 0.873 & 0.848 & 1.000 & & & & & \\
\hline GHQ-12 Total & 0.667 & 0.249 & 0.226 & 0.733 & 0.774 & 0.702 & 1.000 & & & & \\
\hline Age categories & -0.187 & -0.445 & -0.217 & -0.297 & -0.233 & -0.045 & -0.156 & 1.000 & & & \\
\hline Gender & 0.698 & -0.106 & 0.164 & 0.656 & 0.576 & 0.855 & 0.458 & -0.023 & 1.000 & & \\
\hline $\begin{array}{l}\text { COVID-19 } \\
\text { related } \\
\text { symptoms }\end{array}$ & 0.210 & 0.136 & 0.220 & 0.520 & 0.495 & 0.319 & 0.397 & 0.025 & 0.020 & 1.000 & \\
\hline $\begin{array}{l}\text { Changing of } \\
\text { mansion due to } \\
\text { the COVID-19 } \\
\text { pandemic }\end{array}$ & 0.556 & 0.372 & 0.057 & 0.466 & 0.582 & 0.502 & 0.538 & -0.091 & 0.147 & -0.010 & 1.000 \\
\hline
\end{tabular}

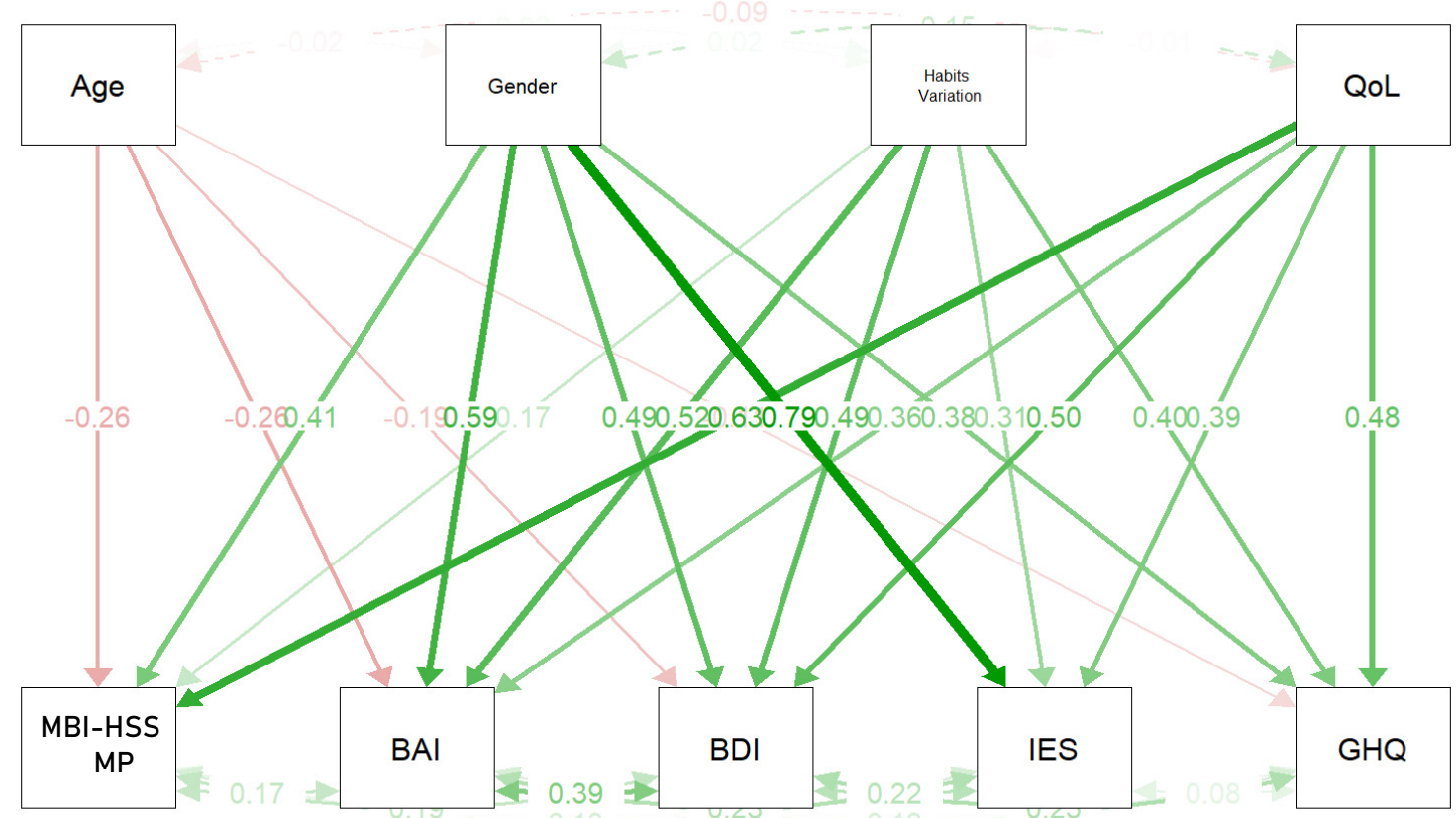

Figure 4. Mediation analysis with covariances (Age categories, Gender, Age categories, Gender, COVID-19 related symptoms, Changing of mansion due to the COVID-19 pandemic). Correlations among Medical Personnel (MBI-HSS MP), Beck Depression Inventory (BDI-II), Beck Anxiety Inventory (BAI), Impact of Event Scale (IES) and General Health Questionnaire 12 Items (GHQ-12). 


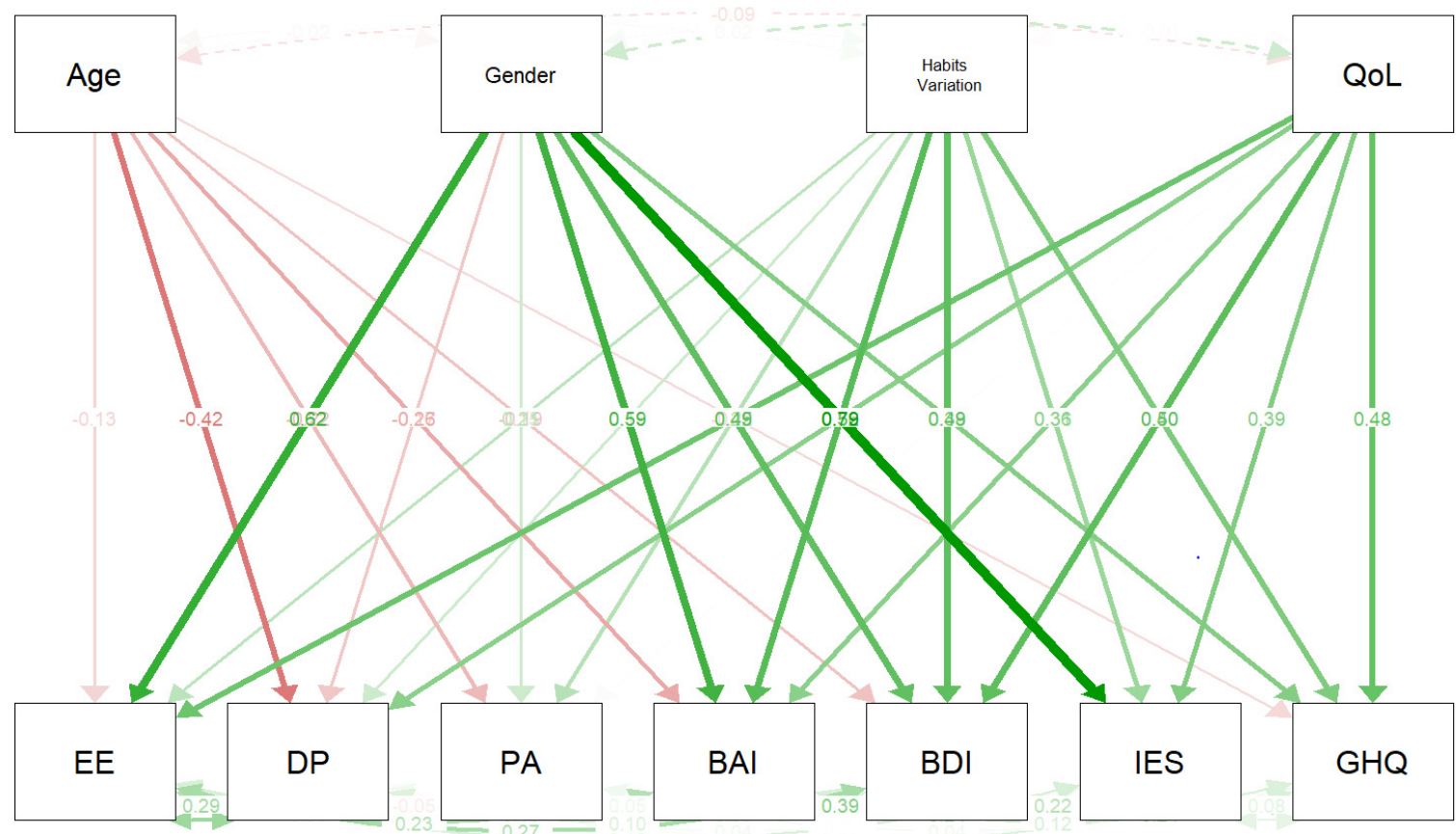

Figure 5. Mediation analysis with covariances (Age categories, Gender, Age categories, Gender, COVID-19 related symptoms, Changing of mansion due to the COVID-19 pandemic). Legend: Correlations among Emotional Exhaustion (EE), Depersonalization (DP), Personal Accomplishment (PA), Beck Depression Inventory (BDI-II), Beck Anxiety Inventory (BAI), Impact of Event Scale (IES) and General Health Questionnaire 12 Items (GHQ-12). QoL = Impact of COVID-19 pandemic on Quality of Life (QoL).

Table 4. Regression, covariance, intercept, and variance of Maslach Burnout Inventory-Human Services Survey for Medical Personnel (MBI-HSS MP), Beck Depression Inventory (BDI), Beck Anxiety Inventory (BAI), Impact of Event Scale (IES) and General Health Questionnaire (GHQ).

\begin{tabular}{|c|c|c|c|c|c|c|c|c|}
\hline & & Variables & Estimate & Standard Error & Z-Value & $P(>|z|)$ & Std. $1 v$ & Std. All \\
\hline \multirow{12}{*}{ Regression } & \multirow{4}{*}{$\begin{array}{l}\text { Maslach } \\
\text { Total }\end{array}$} & Age categories & -0.835 & 0.059 & -14.187 & $<0.001$ & -0.835 & -0.261 \\
\hline & & Gender & 1.894 & 0.085 & 22.357 & $<0.001$ & 1.894 & 0.414 \\
\hline & & COVID-19 related symptoms & 1.038 & 0.110 & 9.427 & $<0.001$ & 1.038 & 0.173 \\
\hline & & $\begin{array}{l}\text { Changing of mansion due to } \\
\text { the COVID-19 pandemic }\end{array}$ & 3.936 & 0.116 & 33.995 & $<0.001$ & 3.936 & 0.633 \\
\hline & \multirow{4}{*}{$\begin{array}{l}\text { BAI } \\
\text { Total }\end{array}$} & Age categories & -1.259 & 0.059 & -21.380 & $<0.001$ & -1.259 & -0.265 \\
\hline & & Gender & 1.894 & 0.085 & 22.357 & $<0.001$ & 1.894 & 0.414 \\
\hline & & COVID-19 related symptoms & 1.038 & 0.110 & 9.427 & $<0.001$ & 1.038 & 0.173 \\
\hline & & $\begin{array}{l}\text { Changing of mansion due to } \\
\text { the COVID- } 19 \text { pandemic }\end{array}$ & 3.936 & 0.116 & 33.995 & $<0.001$ & 3.936 & 0.633 \\
\hline & \multirow{4}{*}{$\begin{array}{l}\text { BDI-II } \\
\text { Total }\end{array}$} & Age categories & -0.760 & 0.059 & -12.901 & $<0.001$ & -0.760 & -0.190 \\
\hline & & Gender & 2.792 & 0.085 & 32.957 & $<0.001$ & 2.792 & 0.488 \\
\hline & & COVID-19 related symptoms & 3.716 & 0.110 & 33.746 & $<0.001$ & 3.716 & 0.495 \\
\hline & & $\begin{array}{l}\text { Changing of mansion due to } \\
\text { the COVID-19 pandemic }\end{array}$ & 3.878 & 0.116 & 33.500 & $<0.001$ & 3.878 & 0.498 \\
\hline
\end{tabular}


Table 4. Cont.

\begin{tabular}{|c|c|c|c|c|c|c|c|c|}
\hline & & Variables & Estimate & Standard Error & Z-Value & $P(>|z|)$ & Std. lv & Std. All \\
\hline & \multirow{4}{*}{$\begin{array}{l}\text { IES } \\
\text { Total }\end{array}$} & Age categories & -0.001 & 0.059 & -0.018 & $<0.001$ & -0.001 & -0.000 \\
\hline & & Gender & 9.650 & 0.085 & 113.896 & $<0.001$ & 9.650 & 0.791 \\
\hline & & COVID-19 related symptoms & 4.908 & 0.110 & 44.576 & $<0.001$ & 4.908 & 0.306 \\
\hline & & $\begin{array}{l}\text { Changing of mansion due to } \\
\text { the COVID- } 19 \text { pandemic }\end{array}$ & 6.453 & 0.116 & 55.741 & $<0.001$ & 6.453 & 0.389 \\
\hline & \multirow{4}{*}{$\begin{array}{l}\text { GHQ- } \\
12 \\
\text { total }\end{array}$} & Age categories & -0.273 & 0.059 & -4.636 & $<0.001$ & -0.273 & -0.115 \\
\hline & & Gender & 1.283 & 0.085 & 15.145 & $<0.001$ & 1.283 & 0.377 \\
\hline & & COVID-19 related symptoms & 1.775 & 0.110 & 16.122 & $<0.001$ & 1.775 & 0.397 \\
\hline & & $\begin{array}{l}\text { Changing of mansion due to } \\
\text { the COVID- } 19 \text { pandemic }\end{array}$ & 2.208 & 0.116 & 19.074 & $<0.001$ & 2.208 & 0.476 \\
\hline \multirow{10}{*}{ Covariance } & \multirow{4}{*}{$\begin{array}{l}\text { Maslach } \\
\text { Total }\end{array}$} & BAI Total & 0.175 & 0.037 & 4.690 & $<0.001$ & 0.175 & 0.175 \\
\hline & & BDI-II Total & 0.185 & 0.037 & 5.001 & $<0.001$ & 0.185 & 0.185 \\
\hline & & IES Total & 0.128 & 0.038 & 3.358 & 0.001 & 0.128 & 0.128 \\
\hline & & GHQ-12 total & 0.067 & 0.039 & 1.735 & 0.083 & 0.067 & 0.067 \\
\hline & \multirow{3}{*}{$\begin{array}{l}\text { BAI } \\
\text { Total }\end{array}$} & BDI-II Total & 0.389 & 0.031 & 12.552 & $<0.001$ & 0.389 & 0.389 \\
\hline & & IES Total & 0.232 & 0.036 & 6.457 & $<0.001$ & 0.232 & 0.232 \\
\hline & & GHQ-12 total & 0.121 & 0.038 & 3.191 & 0.001 & 0.121 & 0.121 \\
\hline & \multirow{2}{*}{$\begin{array}{l}\text { BDI-II } \\
\text { Total }\end{array}$} & IES Total & 0.218 & 0.036 & 6.013 & $<0.001$ & 0.218 & 0.218 \\
\hline & & GHQ-12 total & 0.245 & 0.036 & 6.867 & $<0.001$ & 0.245 & 0.245 \\
\hline & $\begin{array}{l}\text { IES } \\
\text { Total }\end{array}$ & GHQ-12 total & 0.076 & 0.039 & 1.957 & 0.050 & 0.076 & 0.076 \\
\hline \multirow{5}{*}{ Intercept } & \multicolumn{2}{|c|}{ Maslach total } & 57.394 & 0.217 & 264.068 & $<0.001$ & 57.394 & 26.887 \\
\hline & \multicolumn{2}{|c|}{ BAI Total } & 2.789 & 0.217 & 12.834 & $<0.001$ & 2.789 & 0.878 \\
\hline & \multicolumn{2}{|c|}{ BDI-II Total } & 2.903 & 0.217 & 13.355 & $<0.001$ & 2.903 & 1.086 \\
\hline & \multicolumn{2}{|c|}{ IES total } & -1.512 & 0.217 & -6.957 & $<0.001$ & -1.512 & -0.265 \\
\hline & \multicolumn{2}{|c|}{ GHQ-12 Total } & 15.725 & 0.217 & 72.350 & $<0.001$ & 15.725 & 9.889 \\
\hline \multirow{5}{*}{ Variance } & \multicolumn{2}{|c|}{ Maslach total } & 1.000 & & & & 1.000 & 0.219 \\
\hline & \multicolumn{2}{|c|}{ BAI Total } & 1.000 & & & & 1.000 & 0.099 \\
\hline & \multicolumn{2}{|c|}{ BDI-II Total } & 1.000 & & & & 1.000 & 0.140 \\
\hline & \multicolumn{2}{|c|}{ IES total } & 1.000 & & & & 1.000 & 0.031 \\
\hline & \multicolumn{2}{|c|}{ GHQ-12 Total } & 1.000 & & & & 1.000 & 0.395 \\
\hline
\end{tabular}

Legend. Standardized latent variable coefficient (std.lv), Standardized coefficient (std. all).

Table 5. Regression and covariance, intercept of Emotional Exhaustion (EE), Depersonalization (DP), Personal Accomplishment (PA), Beck Depression Inventory (BDI), Beck Anxiety Inventory (BAI), Impact of Event Scale (IES) and General Health Questionnaire 12 Items (GHQ).

\begin{tabular}{|c|c|c|c|c|c|c|}
\hline \multicolumn{3}{|c|}{ Variables } & \multirow{2}{*}{$\begin{array}{c}\text { Estimate } \\
-0.0399 \\
\end{array}$} & \multirow{2}{*}{$\begin{array}{c}\text { Standard Error } \\
0.059\end{array}$} & \multirow{2}{*}{$\begin{array}{c}\text { Z-Value } \\
-6.774\end{array}$} & \multirow{2}{*}{$\frac{P(>|z|)}{<0.001}$} \\
\hline \multirow{8}{*}{ Regression } & \multirow{4}{*}{ Emotional Exhaustion (EE) } & Age categories & & & & \\
\hline & & Gender & 2.702 & 0.085 & 31.888 & $<0.001$ \\
\hline & & COVID-19 related symptoms & 1.167 & 0.110 & 10.596 & $<0.001$ \\
\hline & & $\begin{array}{l}\text { Changing of mansion due to the } \\
\text { COVID-19 pandemic }\end{array}$ & 2.673 & 0.116 & 23.092 & $<0.001$ \\
\hline & \multirow{4}{*}{ Depersonalization (DP) } & Age categories & -0.785 & 0.059 & -13.337 & $<0.001$ \\
\hline & & Gender & -0.459 & 0.085 & -5.413 & $<0.001$ \\
\hline & & COVID-19 related symptoms & 0.540 & 0.110 & 4.904 & $<0.001$ \\
\hline & & $\begin{array}{l}\text { Changing of mansion due to the } \\
\text { COVID-19 pandemic }\end{array}$ & 1.314 & 0.116 & 11.353 & $<0.001$ \\
\hline
\end{tabular}


Table 5. Cont

\begin{tabular}{|c|c|c|c|c|c|c|}
\hline \multicolumn{3}{|c|}{ Variables } & Estimate & Standard Error & Z-Value & $P(>|z|)$ \\
\hline & \multirow{4}{*}{ Personal Accomplishment (PA) } & Age categories & -0.349 & 0.059 & -5.925 & $<0.001$ \\
\hline & & Gender & 0.349 & 0.085 & 4.116 & $<0.001$ \\
\hline & & COVID-19 related symptoms & 0.669 & 0.110 & 6.072 & $<0.001$ \\
\hline & & $\begin{array}{l}\text { Changing of mansion due to the } \\
\text { COVID-19 pandemic }\end{array}$ & 0.052 & 0.116 & 0.448 & 0.654 \\
\hline & \multirow{4}{*}{ BAI Total } & Age categories & -1.259 & 0.059 & -21.380 & $<0.001$ \\
\hline & & Gender & 3.987 & 0.085 & 47.058 & $<0.001$ \\
\hline & & COVID-19 related symptoms & 4.630 & 0.110 & 42.051 & $<0.001$ \\
\hline & & $\begin{array}{l}\text { Changing of mansion due to the } \\
\text { COVID-19 pandemic }\end{array}$ & 3.336 & 0.116 & 28.815 & $<0.001$ \\
\hline & \multirow{4}{*}{ BDI-II Total } & Age categories & -0.769 & 0.059 & -12.901 & $<0.001$ \\
\hline & & Gender & 2.792 & 0.085 & 32.958 & $<0.001$ \\
\hline & & COVID-19 related symptoms & 3.716 & 0.110 & 33.747 & $<0.001$ \\
\hline & & $\begin{array}{l}\text { Changing of mansion due to the } \\
\text { COVID-19 pandemic }\end{array}$ & 3.878 & 0.116 & 33.500 & $<0.001$ \\
\hline & \multirow{4}{*}{ IES Total } & Age categories & -0.001 & 0.059 & -0.016 & 0.987 \\
\hline & & Gender & 9.650 & 0.085 & 113.896 & $<0.001$ \\
\hline & & COVID-19 related symptoms & 4.908 & 0.110 & 44.576 & $<0.001$ \\
\hline & & $\begin{array}{l}\text { Changing of mansion due to the } \\
\text { COVID-19 pandemic }\end{array}$ & 6.453 & 0.116 & 55.740 & $<0.001$ \\
\hline & \multirow{4}{*}{ GHQ-12 total } & Age categories & -0.273 & 0.059 & -4.638 & $<0.001$ \\
\hline & & Gender & 1.283 & 0.085 & 15.145 & $<0.001$ \\
\hline & & COVID-19 related symptoms & 1.775 & 0.110 & 16.122 & $<0.001$ \\
\hline & & $\begin{array}{l}\text { Changing of mansion due to the } \\
\text { COVID-19 pandemic }\end{array}$ & 2.208 & 0.116 & 19.072 & $<0.001$ \\
\hline \multirow{21}{*}{ Covariance } & \multirow{6}{*}{ Emotional Exhaustion (EE) } & Depersonalization (DP) & 0.294 & 0.034 & 8.560 & $<0.001$ \\
\hline & & Personal Accomplishment (PA) & 0.055 & 0.039 & 1.423 & 0.155 \\
\hline & & BAI Total & 0.234 & 0.036 & 6.519 & $<0.001$ \\
\hline & & BDI-II Total & 0.271 & 0.035 & 7.758 & $<0.001$ \\
\hline & & IES Total & 0.122 & 0.038 & 3.197 & 0.001 \\
\hline & & GHQ-12 total & 0.111 & 0.038 & 2.900 & 0.004 \\
\hline & \multirow{5}{*}{ Depersonalization (DP) } & Personal Accomplishment (PA) & -0.051 & 0.039 & -1.301 & 0.193 \\
\hline & & BAI Total & 0.100 & 0.038 & 2.616 & 0.009 \\
\hline & & BDI-II Total & 0.102 & 0.038 & 2.653 & 0.008 \\
\hline & & IES Total & 0.041 & 0.039 & 1.042 & 0.297 \\
\hline & & GHQ-12 total & 0.012 & 0.039 & 0.317 & 0.751 \\
\hline & \multirow{4}{*}{ Personal Accomplishment (PA) } & BAI Total & 0.047 & 0.039 & 1.198 & 0.231 \\
\hline & & BDI-II Total & 0.088 & 0.039 & 2.266 & 0.023 \\
\hline & & IES Total & -0.004 & 0.039 & -0.106 & 0.916 \\
\hline & & GHQ-12 total & 0.042 & 0.039 & 1.080 & 0.280 \\
\hline & \multirow{3}{*}{ BAI Total } & BDI-II Total & 0.390 & 0.031 & 12.607 & $<0.001$ \\
\hline & & IES Total & 0.237 & 0.036 & 6.617 & $<0.001$ \\
\hline & & GHQ-12 total & 0.119 & 0.038 & 3.125 & 0.002 \\
\hline & \multirow{2}{*}{ BDI-II Total } & IES Total & 0.223 & 0.036 & 6.178 & $<0.001$ \\
\hline & & GHQ-12 total & 0.239 & 0.036 & 6.671 & $<0.001$ \\
\hline & IES Total & GHQ-12 total & 0.077 & 0.039 & 2.003 & 0.045 \\
\hline
\end{tabular}


Table 6. Intercept and variance of Emotional Exhaustion (EE), Depersonalization (DP), Personal Accomplishment (PA), Beck Depression Inventory (BDI), Beck Anxiety Inventory (BAI), Impact of Event Scale (IES) and General Health Questionnaire (GHQ).

\begin{tabular}{|c|c|c|c|c|c|c|c|}
\hline & Variables & Estimate & Standard Error & Z-Value & $P(>|z|)$ & Std. lv & Std. all \\
\hline \multirow{7}{*}{ Intercept } & Emotional Exhaustion (EE) & 13.465 & 0.217 & 61.953 & $<0.001$ & 13.465 & 6.662 \\
\hline & Depersonalization (DP) & 12.200 & 0.217 & 56.131 & $<0.001$ & 12.200 & 9.761 \\
\hline & Personal Accomplishment (PA) & 68.272 & 0.217 & 314.117 & $<0.001$ & 68.272 & 63.953 \\
\hline & BAI Total & 2.789 & 0.217 & 12.834 & $<0.001$ & 2.790 & 0.878 \\
\hline & BDI Total & 2.903 & 0.217 & 13.355 & $<0.001$ & 2.903 & 1.086 \\
\hline & IES total & -1.512 & 0.217 & -6.957 & $<0.001$ & -1.512 & -0.265 \\
\hline & GHQ Total & 15.725 & 0.217 & 72.352 & $<0.001$ & 15.725 & 9.890 \\
\hline \multirow{7}{*}{ Variance } & Emotional Exhaustion (EE) & 1.000 & & & & 1.000 & 0.245 \\
\hline & Depersonalization (DP) & 1.000 & & & & 1.000 & 0.640 \\
\hline & Personal Accomplishment (PA) & 1.000 & & & & 1.000 & 0.877 \\
\hline & BAI Total & 1.000 & & & & 1.000 & 0.099 \\
\hline & BDI Total & 1.000 & & & & 1.000 & 0.140 \\
\hline & IES total & 1.000 & & & & 1.000 & 0.031 \\
\hline & GHQ Total & 1.000 & & & & 1.000 & 0.396 \\
\hline
\end{tabular}

Legend. Standardized latent variable coefficient (std.lv), Standardized coefficient (std. all).

Considering EE, D, and PA singularly, statistically significant effects were found as follows: age categories on low PA $(\beta=-0.217)$; gender on $\mathrm{EE}(\beta=0.698)$ and on low PA ( $\beta=0.164)$; changing of mansion due to the COVID-19 on EE $(\beta=0.556)$ and on low PA (0.057), health perception $(\beta=0.538)$, depression $(\beta=0.582)$, perceived stress $(\beta=0.502)$.

The SEM estimated RMSEA fit is equal to 0.075 indicating a suitable model fit.

\section{Discussion}

The 2019-nCOVID pandemic as a public health emergency has presented healthcare systems with remarkable challenges. The current research expands the findings of a previously published study, to deepen the understanding of the mental health effects of the 2019-nCOVID pandemic on HCWs from North-eastern Piedmont, Italy. In the first work [23], we evaluated singularly burnout, anxiety, depression, distress, observing higher degrees of burnout (in particular D and PA) in females, in HCWs aged $<30$ years, in those exposed to changes in their working habits and their families' behavior, and in trainees. Moreover, lower ranges of anxiety and depression than those reported in the literature were found.

To our knowledge, this study was the first to explore the relationship among job burnout, depression, anxiety, perceived stress, health perception in Italian HCWs, examining the possible role of the following factors as mediators of the aforesaid relationships: gender, age categories, COVID-19 related symptoms, changing of mansion due to the COVID-19 pandemic.

We wanted to investigate, by utilizing mediation analysis, whether a variable (i.e., mediator) adjustment regarding an impartial variable, in turn, affects a structured variable. Moderation evaluation, however, investigates whether the statistical interplay between impartial variables expects an established variable, with a specific interest in the role of the three scales of job burnout.

Only $37 \%$ of HCWs responded to the emailed survey. The low response rates highlighted a possible lack of interest in participating in the study in a tragic and unexpected historical period such as the pandemic, which has led to an upheaval in family and work habits; the length of the survey; the absence of certainty of protection of privacy and confi- 
dentiality are all factors. As described in a previous study [31], the COVID-19 pandemic has led to survey fatigue characterized by non-response, with a consequent decrease of response rate during the pandemic. This could be explained by the fact that during the COVID-19 pandemic, the number of surveys created and disseminated has increased significantly with the consequence that HCWs may feel overwhelmed with the number of survey requests, also due to the great increase in social media dissemination during the COVID-19 pandemic that can contribute to the illusion that survey requests are omnipresent.

The results of this study highlighted statistically significant effects of perceived stress and health perception on both anxiety and depression, and effects of depression on anxiety. As for job burnout, we found statistically significant effects of EE on D, PA, anxiety, depression, and health perception. The statistical correlation between D and a low PA was highlighted, indicative of higher burnout. Finally, effects of a low PA were significantly correlated with perceived stress, anxiety, health perception, and depression.

Four covariates were included in the mediation analysis: age, gender, COVID-19 related symptoms, changing of mansion due to the COVID-19 pandemic.

Findings suggested the following: age categories impact on low PA; gender impacts on anxiety and psychological distress; changing of mansion due to the COVID-19 pandemic impacts on health perception, depression, perceived stress, EE, and low PA; COVID-19 related symptoms have statistically significant effects on anxiety.

Using the structural equation model (SEM), Song et al. [32] described that both tension and poor rest showed associations with job burnout among Chinese nurses. The SEM analysis confirmed the direct pathway from perceived stress to burnout $(\beta=0.69, p<0.05)$ and the indirect pathway mediated by sleep quality $(\beta=0.56)$. There existed statistically significant effects of sleep quality on both perceived stress $(\beta=0.48)$ and job burnout $(\beta=0.29)$. Nonetheless, in our study, we did not analyze the quality of the sleep-wake rhythm and our sample included different groups of HCWs; therefore, the possibility to compare our results to those by Song and coworkers is limited. Notwithstanding these limitations, it is true that a correlation between perceived stress and job burnout has been found in both works, even though the effect of low PA (high burnout) on perceived stress was more evident in this study.

A Turkish study [33] aimed to examine the mediating role of optimism and social relationships on the development of burnout among HCWs during the COVID-19 pandemic. Women reported greater strain from the COVID-19, greater emotional exhaustion, and fewer social relationships. HCWs with COVID-19 disease reported less optimism. The findings suggested that stress and anxiety not only had a direct effect on increasing COVID-19 burnout but also had an indirect effect on it through a decrease in positive outlook and social connections. Even if our work did not specifically investigate social relationships, it was observed that changing of mansion due to the COVID-19 pandemic had an impact on health perception, depression, perceived stress, and burnout (high EE and low PA); moreover, in our sample, HCWs with COVID-19 related symptoms reported higher levels of anxiety symptoms.

A national cross-sectional survey conducted in the U.S. analyzed the prevalence and correlates of stress and burnout among HCWs during the COVID-19 pandemic [34]. Higher Summary Stress Score (SSS) which included stress, fear of exposure, anxiety/depression, and workload were highlighted among nursing assistants, medical assistants, social workers, inpatients, women, and black individuals; moreover, the results appeared to be related to workload and mental health, and the SSS score was lower when health professionals felt valued. The workload in our study was objectified through the change of mansion due to the COVID-19 pandemic, which led to a worsening of perceived health, an increase in distress, depression, and job burnout (high EE, low PA). Gender also appears to impact anxiety symptoms and psychological distress as found in the previously cited study.

In a Portuguese study analyzing the mediating role of psychological resilience of HCWs during the COVID-19 pandemic on burnout and depression [35], the outcomes revealed that clinical depression had a direct guided effect on the individual, job- and 
also patient-related burnout, as in our study, where it found the correlation between depression and EE, in addition to the strong correlation with anxiety. Moreover, Serrão et al. [35] also observed a small indirect impact of depression on burnout, mediated by resilience; resilience played a partial mediating role between anxiety as well as all job burnout measurements.

One study conducted during the first COVID-19 pandemic peak period to analyze the burnout status of Italian HCWs [36] showed that a substantial part of the sample scored over the clinical levels of depression $(57.9 \%)$, anxiety $(65.2 \%)$, post-traumatic symptoms $(55 \%)$, and also burnout $(25.61 \%)$. The burnout variation highlighted in the study by Conti et al. seemed to be independently affected by working on the front line, being doctors, experiencing reductions in mental health, as well as higher levels of post-traumatic stress disorder symptoms, in line with the results of our work. We found that the EE and PA scales of MBI-HSS MP, correlated with anxiety and depression, while D showed a lower impact on them. Moreover, the EE and PA scales seemed to have an impact on HCWs' health perception.

\section{Strengths and Limitations}

Among the strengths of our study was the sample size and the use of validated questionnaires to investigate burnout with anxiety, depression, distress symptoms, and overall mental health. Moreover, our survey was sent to frontline and non-frontline HCWs, recruited both from the health facility as well as from extra-hospital settings, allowing for an in-depth understanding of the pandemic that has had a unique effect on HCWs. Furthermore, data were gathered about socio-demographic, working habits-related, and pandemic-related variables.

Nonetheless, our lookup has some boundaries which need to be underscored. We gathered data solely from a single center in Piedmont, a high-risk though restrained area, in Italy. This is a cross-sectional study, and in accordance with the design, it is challenging to derive causal relationships. As all comparable research in this field, regrettably, goal records about preceding psychiatric issues had been no longer reachable and we did not ask for information about preceding psychiatric history, which may have biased the results we found. We had no availability of preceding measures on the psychological variables investigated, nonetheless, it is probable that, for burnout and perceived timehonored health, ratings worsened throughout the present-day pandemic. It should also be underlined that our study is the first that analyzes the correlation among the scales of MBIHSS MP with others. More specifically, it was highlighted a high correlation between EE and D was highlighted as well as D having a statistically significant effect on the reduction of PA.

Moreover, as in different comparable studies, we used online self-report instruments that are much less inclusive and less precise than an assessment interview performed by a skilled clinician. Finally, the validated scale for the contrast of stress signs and symptoms (COVID-19 IES) [37] had not been used because it was not yet available. Nonetheless, the follow-up of the sample will include COVID-specific measures.

\section{Conclusions}

The COVID-19 pandemic has exposed the general population to challenges never seen before, including restriction of social relationships, and changes in individual and family habits. While supported by institutional and government leadership, the spirit of collaboration, the celebration of saved lives and the public recognition of their relevance, the HCWs have displayed high levels of distress, anxiety, emotional exhaustion, which contributed to increasing feelings of loneliness and the deterioration in their mental health [7].

Our study showed a particularly strong correlation among depression, psychological distress, health perception and anxiety, and the impact of job burnout (high EE) on anxiety, depression, and distress. Gender seemed to have a strong correlation with burnout (High $\mathrm{EE}$ ), anxiety and distress, while the impact of COVID-19 pandemic on Quality of Life (QoL) 
seemed to affect anxiety and depression while changing of mansion due to the COVID-19 pandemic influenced depression and job burnout (high EE).

The long-term influence on the well-being of health care workers has yet to be established. During the COVID-19 pandemic, HCWs experience increased emotional stress and anxiety and, in many cases, depression and mental illness.

Encouraging supportive, motivational, protective, and educational strategies would be recommended to policymakers and managers [16].

Identifying the common mental distress related to the care of people with COVID-19, through the analysis of mediating factors that contribute to increased psychological distress and job burnout, would allow destigmatizing mental illness among HCWs, finalizing prevention, and treatment strategies for this population.

Author Contributions: P.Z., C.G. and E.G. designed the study. D.M., M.P., M.R. and E.G. contributed to disseminating the survey. D.A. performed the statistical analyses. P.Z., C.G. and E.G. drafted the manuscript. All authors revised the manuscript and contributed with relevant intellectual content. All authors have read and agreed to the published version of the manuscript.

Funding: This research received no external funding.

Institutional Review Board Statement: The studies involving human participants were reviewed and approved by Comitato Etico In-teraziendale di Novara, Protocollo 534/CE, Studio n. CE 82/20, approved on 11 May 2020.

Informed Consent Statement: The patients/participants provided their written informed consent to participate in this study.

Data Availability Statement: The raw data supporting the conclusions of this article will be made available by the authors, without undue reservation.

Acknowledgments: The Authors would like to thank all participants for their willingness to complete the survey and for their precious help with this research. All Authors have consented to the acknowledgement. A special thanks to Dr Emilio Chirico.

Conflicts of Interest: The authors declare no conflict of interest.

\section{References}

1. Velavan, T.P.; Meyer, C.G. The COVID-19 Epidemic. Trop. Med. Int. Health 2020, 25, 278-280. [CrossRef]

2. WHO Coronavirus (COVID-19) Dashboard. Available online: https: / / covid19.who.int (accessed on 19 November 2021).

3. Umakanthan, S.; Sahu, P.; Ranade, A.V.; Bukelo, M.M.; Rao, J.S.; Abrahao-Machado, L.F.; Dahal, S.; Kumar, H.; Dhananjaya, K.V. Origin, Transmission, Diagnosis and Management of Coronavirus Disease 2019 (COVID-19). Postgrad. Med. J. 2020, 96, 753.

4. Pappa, S.; Ntella, V.; Giannakas, T.; Giannakoulis, V.G.; Papoutsi, E.; Katsaounou, P. Prevalence of Depression, Anxiety, and Insomnia among Healthcare Workers during the COVID-19 Pandemic: A Systematic Review and Meta-Analysis. Brain. Behav. Immun. 2020, 88, 901-907. [CrossRef] [PubMed]

5. Olivieri, A.; Palù, G.; Sebastiani, G. COVID-19 Cumulative Incidence, Intensive Care, and Mortality in Italian Regions Compared to Selected European Countries. Int. J. Infect. Dis. 2021, 102, 363-368. [CrossRef]

6. Moss, M.; Good, V.S.; Gozal, D.; Kleinpell, R.; Sessler, C.N. A Critical Care Societies Collaborative Statement: Burnout Syndrome in Critical Care Health-Care Professionals. A Call for Action. Am. J. Respir. Crit. Care Med. 2016, 194, 106-113. [CrossRef]

7. Mehta, S.; Machado, F.; Kwizera, A.; Papazian, L.; Moss, M.; Azoulay, É.; Herridge, M. COVID-19: A Heavy Toll on Health-Care Workers. Lancet Respir. Med. 2021, 9, 226-228. [CrossRef]

8. Karlsson, U.; Fraenkel, C.-J. COVID-19: Risks to Healthcare Workers and Their Families. BMJ 2020, 371, m3944. [CrossRef] [PubMed]

9. Aziz, S.; Arabi, Y.M.; Alhazzani, W.; Evans, L.; Citerio, G.; Fischkoff, K.; Salluh, J.; Meyfroidt, G.; Alshamsi, F.; Oczkowski, S.; et al. Managing ICU Surge during the COVID-19 Crisis: Rapid Guidelines. Intensive Care Med. 2020, 46, 1303-1325. [CrossRef]

10. Rabow, M.W.; Huang, C.-H.S.; White-Hammond, G.E.; Tucker, R.O. Witnesses and Victims Both: Healthcare Workers and Grief in the Time of COVID-19. J. Pain Symptom Manag. 2021, 62, 647-656. [CrossRef]

11. Azoulay, E.; De Waele, J.; Ferrer, R.; Staudinger, T.; Borkowska, M.; Povoa, P.; Iliopoulou, K.; Artigas, A.; Schaller, S.J.; Hari, M.S.; et al. Symptoms of Burnout in Intensive Care Unit Specialists Facing the COVID-19 Outbreak. Ann. Intensive Care 2020, 10, 110. [CrossRef] [PubMed]

12. Dimitriu, M.C.T.; Pantea-Stoian, A.; Smaranda, A.C.; Nica, A.A.; Carap, A.C.; Constantin, V.D.; Davitoiu, A.M.; Cirstoveanu, C.; Bacalbasa, N.; Bratu, O.G.; et al. Burnout Syndrome in Romanian Medical Residents in Time of the COVID-19 Pandemic. Med. Hypotheses 2020, 144, 109972. [CrossRef] 
13. Morgantini, L.A.; Naha, U.; Wang, H.; Francavilla, S.; Acar, Ö.; Flores, J.M.; Crivellaro, S.; Moreira, D.; Abern, M.; Eklund, M.; et al. Factors Contributing to Healthcare Professional Burnout during the COVID-19 Pandemic: A Rapid Turnaround Global Survey. PLOS ONE 2020, 15, e0238217. [CrossRef]

14. Carroll, N.; Conboy, K. Normalising the "New Normal": Changing Tech-Driven Work Practices under Pandemic Time Pressure. Int. J. Inf. Manag. 2020, 55, 102186. [CrossRef]

15. Lotta, G.; Fernandez, M.; Pimenta, D.; Wenham, C. Gender, Race, and Health Workers in the COVID-19 Pandemic. Lancet 2021, 397, 1264. [CrossRef]

16. Vizheh, M.; Qorbani, M.; Arzaghi, S.M.; Muhidin, S.; Javanmard, Z.; Esmaeili, M. The Mental Health of Healthcare Workers in the COVID-19 Pandemic: A Systematic Review; Springer: Berlin/Heidelberg, Germany, 2020.

17. Pinho-Gomes, A.-C.; Peters, S.; Thompson, K.; Hockham, C.; Ripullone, K.; Woodward, M.; Carcel, C. Where Are the Women? Gender Inequalities in COVID-19 Research Authorship. BMJ Glob. Health 2020, 5, e002922. [CrossRef] [PubMed]

18. Poncet, M.C.; Toullic, P.; Papazian, L.; Kentish-Barnes, N.; Timsit, J.-F.; Pochard, F.; Chevret, S.; Schlemmer, B.; Azoulay, É. Burnout Syndrome in Critical Care Nursing Staff. Am. J. Respir. Crit. Care Med. 2007, 175, 698-704. [CrossRef] [PubMed]

19. Muller, A.E.; Hafstad, E.V.; Himmels, J.P.W.; Smedslund, G.; Flottorp, S.; Stensland, S.Ø.; Stroobants, S.; Van de Velde, S.; Vist, G.E. The Mental Health Impact of the COVID-19 Pandemic on Healthcare Workers, and Interventions to Help Them: A Rapid Systematic Review; Elsevier Ireland, Ltd.: Amsterdam, The Netherlands, 2020; Volume 293.

20. Khasne, R.W.; Dhakulkar, B.S.; Mahajan, H.C.; Kulkarni, A.P. Burnout among Healthcare Workers during COVID-19 Pandemic in India: Results of a Questionnaire-Based Survey. Indian J. Crit. Care Med. Peer-Rev. Off. Publ. Indian Soc. Crit. Care Med. 2020, 24, 664-671. [CrossRef] [PubMed]

21. Maslach, C.; Jackson, S.E. The Measurement of Experienced Burnout. J. Organ. Behav. 1981, 2, 99-113. [CrossRef]

22. Morse, G.; Salyers, M.P.; Rollins, A.L.; Monroe-DeVita, M.; Pfahler, C. Burnout in Mental Health Services: A Review of the Problem and Its Remediation. Adm. Policy Ment. Health 2012, 39, 341-352. [CrossRef]

23. Gramaglia, C.; Marangon, D.; Azzolina, D.; Guerriero, C.; Lorenzini, L.; Probo, M.; Rudoni, M.; Gambaro, E.; Zeppegno, P. The Mental Health Impact of 2019-NCOVID on Healthcare Workers From North-Eastern Piedmont, Italy. Focus on Burnout. Front. Public Health 2021, 9, 483. [CrossRef]

24. Gil-Monte, P.R. Factorial Validity of the Maslach Burnout Inventory (MBI-HSS) among Spanish Professionals. Rev. Saude Publica 2005, 39, 1-8. [CrossRef] [PubMed]

25. Giorgi, G.; Leon-Perez, J.M.; Castiello D’Antonio, A.; Fiz Perez, F.J.; Arcangeli, G.; Cupelli, V.; Mucci, N. The General Health Questionaire (GHQ-12) in a Sample of Italian Workers: Mental Health at Individual and Organizational Level. World J. Med. Sci. 2014, 11, 47-56.

26. Horowitz, M.; Wilner, N.; Alvarez, W. Impact of Event Scale: A Measure of Subjective Stress. Psychosom. Med. 1979, 41, 209-218. [CrossRef]

27. Toledano-Toledano, F.; Contreras-Valdez, J.A. Validity and Reliability of the Beck Depression Inventory II (BDI-II) in Family Caregivers of Children with Chronic Diseases. PLoS ONE 2018, 13, e0206917. [CrossRef]

28. Beck, A.T.; Epstein, N.; Brown, G.; Steer, R.A. An Inventory for Measuring Clinical Anxiety: Psychometric Properties. J. Consult. Clin. Psychol. 1988, 56, 893-897. [CrossRef]

29. Rosseel, Y. Lavaan: An R Package for Structural Equation Modeling. J. Stat. Softw. 2012, 48, 1-36. [CrossRef]

30. R Core Team. R: A Language and Environment for Statistical Computing; R Foundation for Statistical Computing: Vienna, Austria, 2019.

31. de Koning, R.; Egiz, A.; Kotecha, J.; Ciuculete, A.C.; Ooi, S.Z.Y.; Bankole, N.D.A.; Erhabor, J.; Higginbotham, G.; Khan, M.; Dalle, D.U.; et al. Survey Fatigue During the COVID-19 Pandemic: An Analysis of Neurosurgery Survey Response Rates. Front. Surg. 2021, 8, 690680. [CrossRef]

32. Song, Y.; Yang, F.; Sznajder, K.; Yang, X. Sleep Quality as a Mediator in the Relationship Between Perceived Stress and Job Burnout Among Chinese Nurses: A Structural Equation Modeling Analysis. Front. Psychiatry 2020, 11, 566196. [CrossRef] [PubMed]

33. Yıldırım, M.; Çiçek, I.; Şanlı, M.E. Coronavirus stress and COVID-19 burnout among healthcare staffs: The mediating role of optimism and social connectedness. Curr. Psychol. 2021, 40, 5763-5771. [CrossRef]

34. Prasad, K.; McLoughlin, C.; Stillman, M.; Poplau, S.; Goelz, E.; Taylor, S.; Nankivil, N.; Brown, R.; Linzer, M.; Cappelucci, K.; et al. Prevalence and Correlates of Stress and Burnout among U.S. Healthcare Workers during the COVID-19 Pandemic: A National Cross-Sectional Survey Study. E Clin. Med. 2021, 35, 100879. [CrossRef]

35. Serrão, C.; Duarte, I.; Castro, L.; Teixeira, A. Burnout and Depression in Portuguese Healthcare Workers during the COVID-19 Pandemic-The Mediating Role of Psychological Resilience. Int. J. Environ. Res. Public. Health 2021, 18, 636. [CrossRef] [PubMed]

36. Conti, C.; Fontanesi, L.; Lanzara, R.; Rosa, I.; Doyle, R.L.; Porcelli, P. Burnout Status of Italian Healthcare Workers during the First COVID-19 Pandemic Peak Period. Healthcare 2021, 9, 510. [CrossRef] [PubMed]

37. Vanaken, L.; Scheveneels, S.; Belmans, E.; Hermans, D. Validation of the Impact of Event Scale With Modifications for COVID-19 (IES-COVID19). Front. Psychiatry 2020, 11, 738. [CrossRef] [PubMed] 